\title{
9 \\ Faunal Remains at Man Bac
}

\author{
Junmei Sawadaํ, Nguyen Kim Thuy² and Nguyen Anh Tuan² \\ ${ }^{1}$ St. Marianna University School of Medicine, Kawasaki, Japan \\ ${ }^{2}$ The Vietnamese Institute of Archaeology
}

This chapter describes the zooarchaeological findings from an analysis of the mammalian remains from Man Bac. Several hundred vertebrate remains were recovered during the excavations of Man Bac between 2005 and 2007. Mammalian and fish bones formed the main component of the recovered vertebrate assemblage. These animal bones provide primary information for an understanding of the subsistence behaviours of the Man Bac community during the neolithic and of the palaeoenvironment of the coastal plain where Man Bac is situated.

Previous studies have examined the past mammalian fauna of northern Vietnam (Vu, 1981, 1984; Vu and Nguyen, 1988; Nguyen and Vu, 2004), however, there is limited available data on the quantity and size of the mammalian archaeological assemblages. This report provides quantitative information for the mammalian assemblage as well as supplying raw data on taxonomic identification and the measurements of bones and teeth (see Appendix 9.1 and 9.2 this chapter).

\section{MATERIALS AND METHODS}

The Man Bac faunal assemblage was collected by a combination of in situ recovery during excavation and the intensive sieving of two excavation squares (E3 and G1). While it is believed that all vertebrate remains were recovered, realistically it is likely that some very small vertebrate remains (e.g. rats) may have been missed during excavation and recovery. All of the faunal remains were cleaned and labelled with provenance data in the form of site, date, square, layer, and spit. Taxonomic identification of the mammalian remains was based on cranial and dental morphology. Each specimen was provided with a sample number, then identified, to at least order or family, genus and species level if possible (see Appendix 9.1 this chapter). Cetacea and Muridae were identified from post-cranial bones as no cranial remains for these taxa were recovered. The modern mammalian bone collections in the Vietnam Institute of Archaeology in Hanoi, the Raffles Museum of Biodiversity Research in Singapore, and the National Museum of Nature and Science in Tokyo, were used for comparison and identification. Measurements of cranial and dental remains were taken according to Driesch (1976), the raw data of which are presented in Appendix 9.2 (this chapter).

For Sus scrofa (pig or boar), the dominant species at Man Bac, age-at-death was estimated using the method of Hayashi et al. (1977) based on tooth eruption and attrition of the upper and lower teeth. 


\section{RESULTS}

Ten taxa were recognised, including: Muridae (rat), Canis sp. (dog), Aonyx cinerea (oriental small-clawed otter), Viverra sp. (civet), Rhinoceros sp. (rhinoceros), Sus scrofa (boar), Muntiacus muntjak (barking deer), Cervus sp. (deer), Bos sp. (cattle) and/or Bubalus sp. (water buffalo), and Cetacea (whale/dolphin). With the exception of the Rhinoceros these taxa still inhabit northern Vietnam (Lekagul and McNeely, 1988; Parr and Hoang, 2008).

Table 9.1 shows the number of identified specimens (NISP) and the minimum number of individuals (MNI) with respect to each layer. NISP and MNI were calculated based on sample-numbered remains. The total NISP is 182 , and the total MNI is 37. The mammalian assemblage by percent of NISP is shown in Figure 9.1.

Sus scrofa is the dominant taxon in the Man Bac faunal assemblage $179.1 \%$ of total NISP; $54.1 \%$ of total MNI). The age composition of the Sus remains is shown in Table 9.2 (see also Figure 9.2), and the molar measurements are given in Table 9.3. Sus remains may include a few wild boar, but most Sus remains are considered to be domesticated. Further information on Sus is discussed below.

Family Cervidae (deer) has a significant presence in the assemblge and consisted of Cervus sp. (6.6\% of total NISP; $8.1 \%$ of total MNI) and Muntiacus muntjak $(1.1 \%$ of total NISP; $5.4 \%$ of total MNI). Cervus remains are similar in size to a mediumsize deer, such as C. unicolor (sambar), C. nippon (sika deer), or C. eldii (Eld's deer), and were difficult to identify to the species level.

The Bovinae remains consisted of two molars of a large bovine. They appeared to be Bos sp. and/or Bubalus sp. There is the possibility that Bovinae were already domesticated in Vietnam during the mid Holocene (Vu, 1981). However, we could not find evidence for domestication of Bovinae in the Man Bac site, since the Bovinae remains are too few and fragmentary.

The Carnivora remains consisted of several skull fragments of Canis sp., and the teeth of Viverra sp. ( $V$. zibetha (large Indian civet) or $V$. magaspila (large-spotted civet)) and Aonyx cinerea. Canidae remains include Canis, but there is no Cuon (Asian wild dog), a species widely distributed in Vietnam. Canis was domesticated in Southeast Asia during the neolithic, and Canis may have been bred at Man Bac.

Rhinoceros sp. remains consisted of two molars, and are similar to Rhinoceros sondaicus (Javan rhinoceros).

The Cetacean remains consisted of only one vertebra and fragments of one limb bone. Family, genus and species were indeterminate.

The Muridae remains consisted of a single femur of a small rat.

\section{DISCUSSION}

\section{Domestication of Sus scrofa}

The very high proportion of the mammalian assemblage attributable to Sus is very different from the faunal signatures of hunting and gathering communities, such as during the Hoabinhian period (Nguyen and Vu, 2004; Sawada and Vu, 2006). The demographic profile of the Sus assemblage (Table 9.2, Figure 9.2) demonstrates a very high proportion of juvenile and young-adult individuals. In general, the observed patterns in domestic Sus populations are characterised by an early kill-off 
(Hongo and Meadow, 2000; Hongo et al., 2007), although a high proportion of young Sus remains alone does not necessarily equate with domestication (Albarella et al., 2006). However, the high number and young-biased age distribution of the Man Bac Sus series is indicative of a domesticated population. On the other hand, the morphological features of the Man Bac Sus assemblage are consistent with wild pigs, making it difficult to rule out the possibility that some portion of the sample is wild, rather than domesticated.

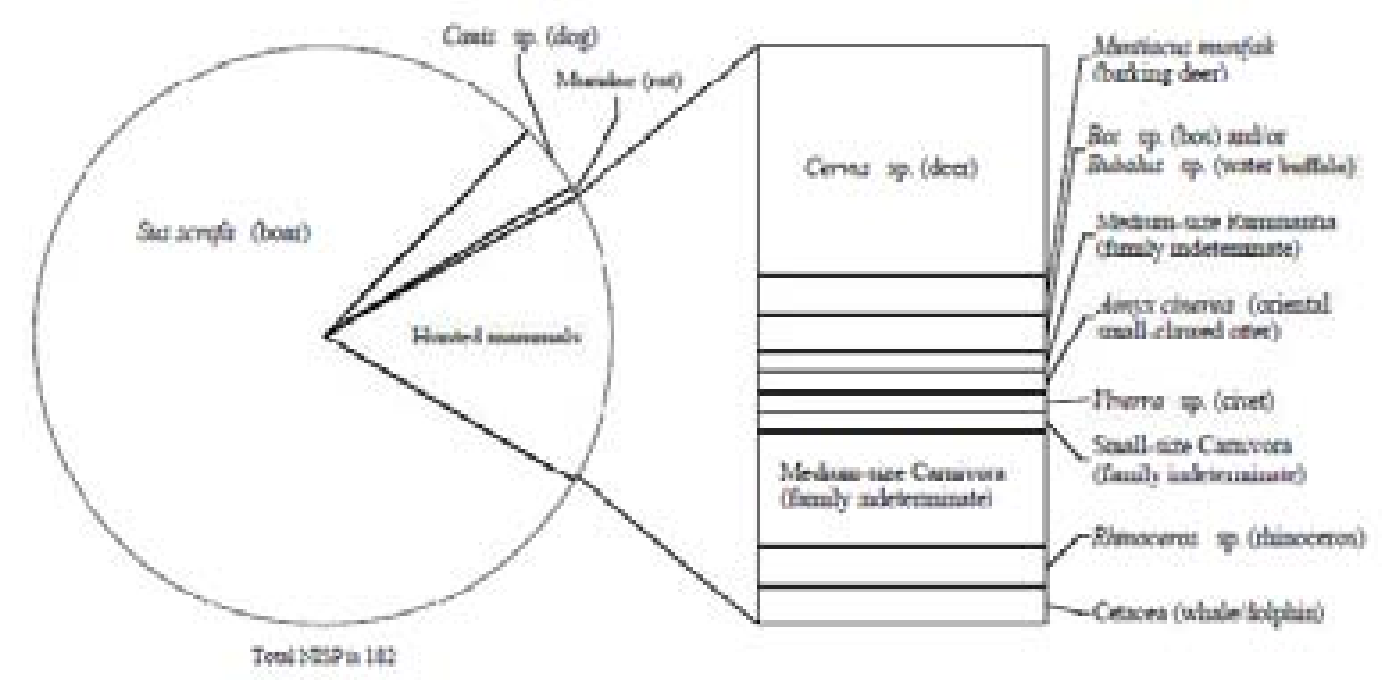

Figure 9.1 Man Bac mammalian assemblage by percent of NISP.

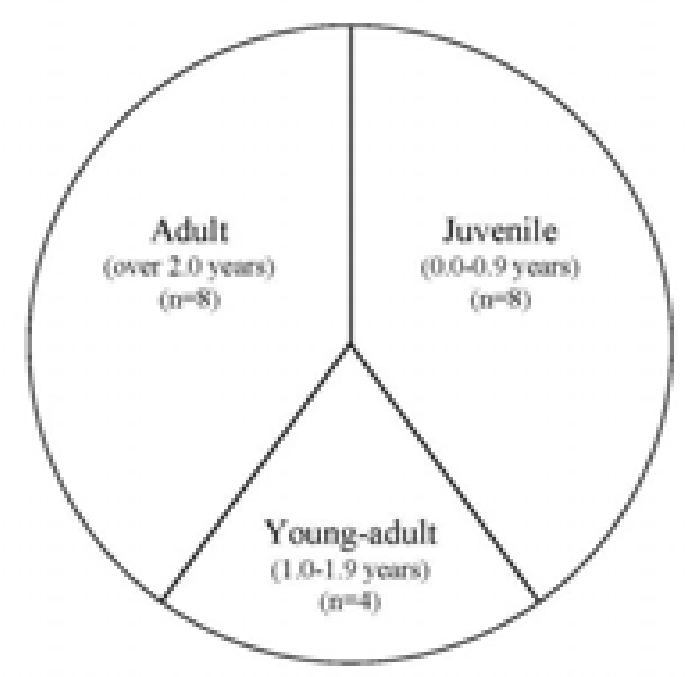

Figure 9.2 Demographic structure of the Man Bac Sus scrofa. 
SAWADA ET AL.

Table 9.1 Mammalian fauna of Man Bac.

\begin{tabular}{|c|c|c|c|c|c|c|c|c|}
\hline \multirow[b]{2}{*}{ Taxon } & \multicolumn{2}{|c|}{ Layer I } & \multicolumn{2}{|c|}{ Layer II } & \multicolumn{2}{|c|}{ Layer III } & \multicolumn{2}{|c|}{ Total } \\
\hline & NISP (\%) & MNI (\%) & NISP (\%) & MNI (\%) & NISP (\%) & MNI (\%) & NISP (\%) & MNI (\%) \\
\hline \multicolumn{9}{|l|}{ Order Rodentia } \\
\hline Muridae (rat) & & & $1(1.7)$ & $1(6.3)$ & & & $1(0.5)$ & $1(2.7)$ \\
\hline \multicolumn{9}{|l|}{ Order Carnivora } \\
\hline Canis sp. (dog) & $3(2.8)$ & $1(5.9)$ & $4(6.9)$ & $2(12.5)$ & & & $7(3.8)$ & $3(8.1)$ \\
\hline \multicolumn{9}{|l|}{ Aonyx cinerea } \\
\hline (oriental small-clawed otter) & $1(0.9)$ & $1(5.9)$ & & & & & $1(0.5)$ & $1(2.7)$ \\
\hline Viverra sp. (civet) & $1(0.9)$ & $1(5.9)$ & & & & & $1(0.5)$ & $1(2.7)$ \\
\hline \multicolumn{9}{|l|}{ Small-size Carnivora } \\
\hline (family indeterminate) & $1(0.9)$ & - & & & & & $1(0.5)$ & - \\
\hline $\begin{array}{l}\text { Medium-size Carnivora } \\
\text { (family indeterminate) }\end{array}$ & $5(4.7)$ & - & $1(1.7)$ & - & & & $6(3.3)$ & - \\
\hline \multicolumn{9}{|l|}{ Order Perissodactyla } \\
\hline Rhinoceros sp. (rhinoceros) & $1(0.9)$ & $1(5.9)$ & & & $1(5.9)$ & $1(25.0)$ & $2(1.1)$ & $2(5.4)$ \\
\hline \multicolumn{9}{|l|}{ Order Artiodactyla } \\
\hline \multicolumn{9}{|l|}{ Sus scrofa } \\
\hline (domestic/wild boar) & $86(80.4)$ & $10(58.8)$ & $43(74.1)$ & $8(50.0)$ & $15(88.2)$ & $2(50.0)$ & $144(79.1)$ & $20(54.1)$ \\
\hline \multicolumn{9}{|l|}{ Muntiacus muntjak } \\
\hline (barking deer) & $1(0.9)$ & $1(5.9)$ & $1(1.7)$ & $1(6.3)$ & & & $2(1.1)$ & $2(5.4)$ \\
\hline Cervus sp. (deer) & $6(5.6)$ & $1(5.9)$ & $6(10.3)$ & $2(12.5)$ & & & $12(6.6)$ & $3(8.1)$ \\
\hline \multicolumn{9}{|l|}{ Bos sp. (bos) and/or } \\
\hline Bubalus sp. (water buffalo) & $1(0.9)$ & $1(5.9)$ & $1(1.7)$ & $1(6.3)$ & & & $2(1.1)$ & $2(5.4)$ \\
\hline \multicolumn{9}{|l|}{ Medium-size Ruminantia } \\
\hline \multicolumn{9}{|l|}{ Order Cetacea } \\
\hline Cetacea (whale/dolphin) & & & $1(1.7)$ & $1(6.3)$ & $1(5.9)$ & $1(25.0)$ & $2(1.1)$ & $2(5.4)$ \\
\hline Total & $107(100.0)$ & $17(100.0)$ & $58(100.0)$ & $16(100.0)$ & $17(100.0)$ & $4(100.0)$ & $182(100.0)$ & $37(100.0)$ \\
\hline
\end{tabular}

Table 9.2 Age composition of the Sus dental remains.

\begin{tabular}{|c|c|c|c|c|c|c|c|c|c|c|c|c|c|c|}
\hline & \multicolumn{2}{|c|}{$<7-8$ months } & \multicolumn{2}{|c|}{$7-8$ months } & \multicolumn{2}{|c|}{$19-20$ months } & \multicolumn{2}{|c|}{$31-32$ months } & \multicolumn{2}{|c|}{ 43-44 months } & \multicolumn{2}{|c|}{$55+$ months } & \multicolumn{2}{|c|}{ Total } \\
\hline & NISP & $\mathrm{MNI}$ & NISP & $\mathrm{MNI}$ & NISP & MNI & NISP & $\mathrm{MNI}$ & NISP & $\mathrm{MNI}$ & NISP & $\mathrm{MNI}$ & NISP & $\mathrm{MNI}$ \\
\hline Layer I & 3 & 2 & 10 & 4 & 5 & 1 & 2 & 1 & 2 & 2 & 0 & 0 & 22 & 10 \\
\hline Layer II & 0 & 0 & 5 & 2 & 2 & 2 & 1 & 1 & 5 & 3 & 0 & 0 & 13 & 8 \\
\hline Layer III & 0 & 0 & 0 & 0 & 1 & 1 & 0 & 0 & 2 & 1 & 0 & 0 & 3 & 2 \\
\hline Total & 3 & 2 & 15 & 6 & 8 & 4 & 3 & 2 & 9 & 6 & 0 & 0 & 38 & 20 \\
\hline
\end{tabular}

Age-at-death estimations are according to Hayashi et al. (1977).

Table 9.3 Length of molars of Sus scrofa $(\mathrm{mm})$.

\begin{tabular}{|c|c|c|c|c|c|c|c|c|c|c|c|c|c|c|c|c|}
\hline \multirow[b]{2}{*}{ Tooth } & \multicolumn{4}{|c|}{ Late Neolithic Man Bac } & \multicolumn{4}{|c|}{ Modern wild ${ }^{(a)}$} & \multicolumn{4}{|c|}{ Modern domestic ${ }^{(\mathrm{a})}$} & \multicolumn{4}{|c|}{ Iron Age Noen U-Loke ${ }^{(b)}$} \\
\hline & $\mathrm{N}$ & Mean & SD & Range & $\mathrm{N}$ & Mean & SD & Range & $\mathrm{N}$ & Mean & SD & Range & $\mathrm{N}$ & Mean & SD & Range \\
\hline UM1 & 10 & 17.8 & 1.3 & $15.4-19.7$ & - & - & - & - & - & - & - & - & 66 & 14.4 & 1.1 & $11.6-16.8$ \\
\hline UM2 & 11 & 22.8 & 1.6 & $20.3-26.3$ & - & - & - & - & - & - & - & - & 50 & 17.2 & 1.6 & $14.0-20.0$ \\
\hline UM3 & 5 & 35.5 & 2.3 & $33.5-38.7$ & - & - & - & - & - & - & - & - & 14 & 32.8 & 2.6 & $29.5-38.0$ \\
\hline LM1 & 4 & 18.8 & 0.3 & $18.3-19.0$ & - & - & - & - & - & - & - & - & 129 & 15.2 & 1.2 & $13.0-21.4$ \\
\hline LM2 & 3 & 23.1 & 0.7 & $22.5-23.8$ & - & - & - & - & - & - & - & - & 75 & 18.6 & 1.3 & $15.9-22.8$ \\
\hline LM3 & 4 & 42.9 & 2.7 & $39.0-45.0$ & 13 & 42.7 & 3.83 & $31.1-51.5$ & 7 & 26.8 & 3.3 & $20.2-36.9$ & 14 & 35.6 & 4.1 & $28.4-44.8$ \\
\hline
\end{tabular}

Abbreviations for tooth types are as follows: UM is upper molar, LM is lower molar.

(a) data from Ishiguro et al. (2008) , (b) data from McCaw (2007). 
Molar dimensions of the Man Bac Sus series, Iron Age domestic Sus remains from Noen U-Loke, Thailand (data from McCaw, 2007), and the lower third molar measurements of Vietnamese modern domestic and wild pigs (data from Ishiguro et al., 2008) are shown in Table 9.3. The lower third molars of the Man Bac Sus series are significantly larger than both modern domestic pigs $(\mathrm{p}<0.001)$ and Noen U-Loke domestic Sus $(p<0.01)$ using Turkey's multiple range test, while they are comparable in size to modern wild boar (Figure 9.3). The other teeth of the Man Bac Sus assemblage also tend to be larger than those of the Noen U-Loke remains, although there were no data for equivalent teeth of wild and Vietnamese domestic pigs.

Body, cranium and tooth size tends to decrease through domestication from wild to domestic forms (Flannery, 1983; Zeder, 2006). Ishigro et al. (2008) noted that the tooth size of Vietnamese modern wild pigs is larger than modern domestic pig teeth, with the tooth size distribution of these groups clearly separate. Figure 9.3 demonstrates that domestic Sus third molars in mainland Southeast Asia have reduced in size from the neolithic through to the present. Similarities in dental metrics between Man Bac Sus and Vietnamese modern wild pigs suggests a similarity between the two. It is not improbable that Man Bac Sus are at the initial stages of pig domestication in Vietnam.

$\mathrm{Vu}$ (1981) argued for the presence of domestic Sus remains at the mid Holocene Da But site of Con Co Ngua. However, Higham (1996) notes that Da But sites show no evidence for the cultivation of plants, and were likely hunter-gatherer and fishing settlements. Bellwood (2005) stated that Sus might have been domesticated during the neolithic in Vietnam, but clear evidence has not been found. This analysis of the Man Bac Sus series adds new evidence for the likelihood of Sus domestication in northern Vietnam by at least 3,500 BP. To clarify the timing and nature of Sus domestication in mainland Southeast Asia, there is a need for more work in this region.

\section{Palaeoenvironment and Mammal Hunting}

The Man Bac mammalian remains, with the exception of the Muridae and domestic Sus/Canis, were hunted animals: Aonyx cinerea, Viverra, Rhinoceros, Muntiacus muntjak, Cervus, Bovinae, and Cetacea. The habitats of these wild

Table 9.4 Primary habitats of the hunted mammals from the Man Bac site.

\begin{tabular}{llcc}
\hline Taxon & Primary habitat & NISP (\%) & MNI (\%) \\
\hline Aonyx cinerea (oriental small-clawed otter) & River and estuary & $1(4.5)$ & $1(7.7)$ \\
Viverra sp. (civet) & Forest & $1(4.5)$ & $1(7.7)$ \\
Rhinoceros sp. (rhinoceros) & Forest with a good supply of water & $2(9.1)$ & $2(15.4)$ \\
Muntiacus muntjak (barking deer) & Forest & $2(9.1)$ & $2(15.4)$ \\
Cervus sp. (deer) & Lowlands, grassland, forest & $12(54.5)$ & $3(23.1)$ \\
Bos sp. (bos) and/or Bubalus sp. (water & Forest and grassland (Bos. Sp), & $2(9.1)$ & $2(15.4)$ \\
buffalo) & open forest and swamp in lowlands & $2(9.1)$ & $2(15.4)$ \\
Cetacea (whale/dolphin) & Sea & & \\
Total hunted mammals & & $22(100.0)$ & $13(100.0)$ \\
\hline
\end{tabular}

Habitat data is based on Lekagul and McNeely (1988) and Parr and Hoang (2008). 


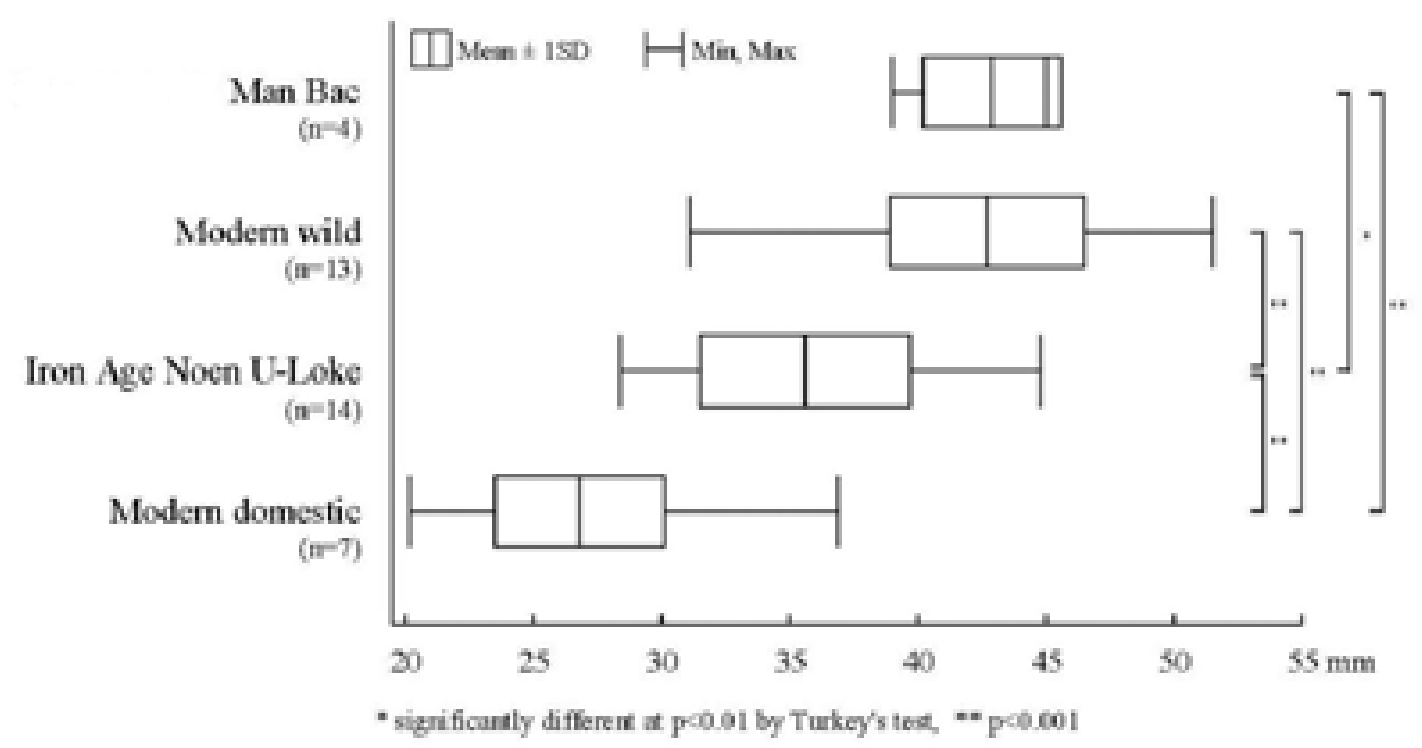

Figure 9.3 Length of lower third molars of the Man Bac Sus series, Iron Age domestic Sus remains from Noen U-Loke in Thailand (data from McCaw, 2007), and Vietnamese modern domestic and wild pigs (data from Ishiguro et al., 2008).

mammals were quite varied and included forest (Viverra sp., Rhinoceros sp., Muntiacus muntjak, Cervus sp., Bos sp., Bubalus sp.), grassland (Cervus sp., Bos sp.), watered places in lowlands (Aonyx cinerea, Rhinoceros sp., Bubalus sp), and the sea (Cetacea) (Lekagul and McNeely, 1988; Parr and Hoang, 2008; Table 9.4). Such varied habitats represent considerable environmental diversity in the vicinity of Man Bac during occupation of the site. Forests, grassland and lowlands can still be seen in the modern landscape near Man Bac, although there are some differences in terms of distance from the sea and probable vegetation types between the present and some 3,500 years ago.

It would appear that the occupants of Man Bac utilised a diverse range of environments for hunting and foraging. Habitat diversity aside, the behaviours and body sizes of the Man Bac mammalian series varied for different species. For instance, the head-body length of Aonyx is $40 \mathrm{~cm}$ whereas that of Rhinoceros is over $3 \mathrm{~m}$ (Lekagul and McNeely, 1988). Given the diversity in both the local environment and physical characteristics of the mammals, Man Bac people likely also lay claim to a diverse range of hunting skills, depending on the type of mammal targeted. Notwithstanding this however, the amount of hunted wild mammal remains $12.1 \%$ of total NISP; $35.1 \%$ of total MNI) is far less than that of the Sus remains. The number of species of hunted wild mammals from the Man Bac site is 7 taxa, which is rather meagre when compared to the species richness of northern Vietnam in the Holocene (Nguyen and Vu, 2004; Parr and Hoang, 2008). In contrast, the Hoabinhian pre-food production sites of northern Vietnam revealed 20 or more species of wild mammals (Nguyen and Vu, 2004; Sawada and Vu, 2006). The taxapoor mammalian assemblage of Man Bac suggests hunting may have been more of a supplementary or secondary subsistence activity, despite the likelihood that they possessed efficient hunting skills. The initiation of domestication during the neolithic reduced the prominence of mammal hunting, and at Man Bac the key mammalian food source was domesticated (but still morphologically wild) pigs. 


\section{CONCLUSIONS}

The Man Bac mammalian assemblage consisted of numerous domestic pig remains with a small number of hunted wild mammals, including several species of deer, bovids, carnivores, rhinoceros and cetaceans. The Man Bac community relied on domesticated pigs as the main mammalian food source, although they likely had sophisticated hunting skills allowing them to target a range of wild mammals in a variety of habitats in relative proximity to the site. The morphology of the pig remains suggests that they were at an initial stage of domestication. The zooarchaeological information of the Man Bac mammalian assemblage analysed in this chapter plays an important role in understanding the food-acquisition strategies of early agricultural societies in northern Vietnam.

\section{SUMMARY}

The Man Bac faunal assemblage provides primary information regarding both the ancient environment and subsistence strategies during the neolithic in northern Vietnam. Mammalian remains formed the main component of the excavated vertebrate assemblage at Man Bac which consisted of a large proportion of domestic pigs and a small number of wild mammals, including several species of deer, bovids, carnivores, rhinoceros and cetaceans. The Man Bac community utilised a range of environments and animal habitats as part of their hunting strategies. However, the relatively small proportion of hunted animals compared to domesticated pig remains suggests a reliance on pigs for their main source of meat. It is believed that Man Bac pigs represent an early stage of domestication.

\section{ACKNOWLEDGMENTS}

We thank the Raffles Museum of Biodiversity Research in Singapore and the National Museum of Nature and Science in Tokyo for access to comparative mammal collections, and Drs. Vu The Long, Nguyen Lan Cuong, Nguyen Kim Dung, Nguyen Mai Huong, Marc F. Oxenham, Hirofumi Matsumura, Mariko Yamagata, Takeji Toizumi, Hitomi Hongo, Masanari Nishimura, and Yukio Dodo for their advice and support.

\section{LITERATURE CITED}

Albarella U, Dobney K, Rowley-Conwy P. 2006. The domestication of the pig (Sus scrofa): new challenges and approaches. In: Zeder MA, Bradley DG, Emshwiller E, Smith BD, editors. Documenting Domestication: New Genetic and Archaeological Paradigms. Berkeley: University of California Press. p 209-227.

Bellwood P. 2005. The First Farmers: Origins of Agricultural Societies. Oxford: Blackwell Publishing.

Driesch A. 1976. A Guide to the Measurement of Animal Bones from Archaeological Sites. Cambridge: Peabody Museum Press.

Flannery KV. 1983. Early pig domestication in the fertile crescent: a retrospective look. In: Young CT, Smith PEL, Mortensen P, editors. The Hilly Flanks and Beyond: Essays on the Prehistory of Southwestern Asia. Chicago: Oriental Institute of the University of 
Chicago. p 163-188.

Hayashi Y, Nishida T, Mochizuki K, Seta S. 1977. Sex and age determination of the Japanese wild boar (Sus scrofa leucomystax) by the lower teeth. Jpn J Vet Sci 39:165174.

Higham CFW. 1996. The Bronze Age of Southeast Asia. Cambridge: Cambridge University Press.

Hongo H, Anezaki T, Yamazaki K, Takahashi O, Sugawara H. 2007. Hunting or management? The status of Sus in the Jomon period in Japan. In: Albarella U, Dobney K, Ervynck A, Rowley-Conwy P, editors. Pigs and Humans: 10,000 Years of Interaction. Oxford: Oxford University Press. p 109-130.

Hongo H, Meadow RH. 2000. Faunal remains from Prepottery Neolithic levels at Çayönü, southeastern Turkey: a preliminary report focusing on pigs (Sus sp.). In: Mashkour M, Choyke AM, Buitenhuis H, Poplin F, editors. Archaeology of the Near East IV A. Groningen: ARC-Publications. p 121-140.

Ishiguro N, Sasaki M, Iwasa M, Shigehara N, Hongo H, Anezaki T, Vu TL, Phan XH, Hguyen XT, Nguyen HN, Vu NT. 2008. Morphological and genetic analysis of Vietnamese Sus scrofa bones for evidence of pig domestication. Anim Sci J 79:655-664.

Lekagul B, McNeely JA. 1988. Mammals of Thailand (2nd edition). Bangkok: Saha Karn Bhaet Co.

McCaw M. 2007. Faunal remains. In: Higham CFW, Kijingam A, Talbot S, editors. The Origins of the Civilization of Angkor, Volume Two, the Excavation of Noen U-Loke and Non Muang Kao. Bangkok: The Thai Fine Arts Department. p 495-536.

Nguyen KS, Vu TL. 2004. Moi Truong \& Van Hoa Cuoi Pleistocene Dau Holocene O Bac Viet Nam. Hanoi: Nha Xuat Ban Khoa Hoc Xa Hoi (in Vietnamese)

Parr JWK, Hoang XT. 2008. A Field Guide to the Large Mammals of Vietnam. Hanoi: People and Nature Reconciliation (Pan Nature).

Sawada J, Vu TL. 2006. Hoabinhian mammal remains from the Hang Cho site, northern Vietnam. In: Matsumura H, editor. Anthropological and Archaeological Study on the Origin of Neolithic People in Mainland Southeast Asia: Report of Grant-in-aid for International Scientific Research (2003 2005 No.15405018), p 83-86.

Vu TL. 1981. Di tich dong vat o Con Co Ngua (Thanh Hoa). Nhung Phat Hien Moi Ve Khao Co Hoc Nam 1980-1:60-6151 (in Vietnamese) .

Vu TL. 1984. So bo nghien cuu nhung xuong rang dong vat va di cot nguoi trong dot khai quat Dong Dau 1984. Nhung Phat Hien Moi Ve Khao Co Hoc Nam 1984:85-89.

Vu TL, Nguyen G. 1988. Xuong dong vat o di chi Cai Beo. Nhung Phat Hien Moi Ve Khao Co Hoc Nam 1987:49-51 (in Vietnamese).

Zeder MA. 2006. Archaeological approaches to documenting animal domestication. In: Zeder MA, Bradley DG, Emshwiller E, Smith BD, editors. Documenting Domestication: New Genetic and Archaeological Paradigms. Berkeley: University of California Press. p 209227. 


\section{FAUNAL REMAINS}

Appendix 9.1 Taxonomic identification.

\begin{tabular}{|c|c|c|c|c|c|c|c|}
\hline Sample No. & Taxon & Skeletal part & $1 / r$ & Layer & Spit & Square & Remarks \\
\hline MB05-184 & Muridae (rat) & Femur & $r$ & $\|$ & 14 & $\mathrm{~b} 1$ & \\
\hline MB07-002 & Canis sp. (dog) & Mandible (with I2, C, P2-P4, M1-M2) & 1 & $\|$ & 10 & f2 & \\
\hline MB05-041 & Canis sp. (dog) & Maxilla (with M1 and M2) & $\mathrm{r}$ & 1 & 7 & d4 & \\
\hline MB05-104 & Canis sp. (dog) & Maxilla (with M1) & $\mathrm{r}$ & $\|$ & 14 & e1 & \\
\hline MB07-013 & Canis sp. (dog) & Maxilla (with $\mathrm{P} 3, \mathrm{P} 4, \mathrm{M} 1$, and $\mathrm{M} 2$ ) & 1 & $\|$ & 11 & e2 & \\
\hline MB05-024 & Canis sp. (dog) & Maxilla (with P4) & $\mathrm{r}$ & I & 6 & d5 & \\
\hline MB05-037 & Canis sp. (dog) & Tooth (UM1) & । & । & 7 & b5 & \\
\hline MB05-088 & Canis sp. (dog) & Tooth (UP4) & I & $\|$ & 10 & $\mathrm{c} 4$ & \\
\hline MB07-047 & Aony $x$ cinerea (oriental small-clawed otter) & Mandible (with $\mathrm{P} 3, \mathrm{P} 4$, and $\mathrm{M} 1$ ) & I & I & 7 & b4 & \\
\hline MB07-020 & Viverra sp. (civet) & Mandible (with C and M1) & $r$ & I & 8 & e1 & \\
\hline MB05-049 & Small-size Carnivora (family indeterminate) & Tooth (LC) & 1 & 1 & 7 & e4 & \\
\hline MB05-039 & Medium-size Carnivora (family indeterminate) & Mandible (ramus of mandible) & I & 1 & 7 & $\mathrm{c} 1$ & \\
\hline MB05-053 & Medium-size Carnivora (family indeterminate) & Mandible (ramus of mandible) & $\mathrm{r}$ & 1 & 7 & a4 & \\
\hline MB05-115 & Medium-size Carnivora (family indeterminate) & Mandible (ramus of mandible) & r & I & 4 & e3 & \\
\hline MB05-047 & Medium-size Carnivora (family indeterminate) & Tooth (fragment of canine) & ? & I & 7 & c2 & \\
\hline MB05-029 & Medium-size Carnivora (family indeterminate) & Tooth (LI3) & । & । & 6 & d5 & \\
\hline MB07-037 & Medium-size Carnivora (family indeterminate) & Tooth (UC) & r & $\|$ & 11 & d2 & \\
\hline MB05-119 & Rhinoceros sp. (rhinoceros) & Tooth (fragment of molar) & ? & । & 6 & a4 & \\
\hline MB05-120 & Rhinoceros sp. (rhinoceros) & Tooth (LM1) & । & III & 14 & b2 & \\
\hline MB05-135 & Sus scrofa (domestic/wild boar) & Fragment of skull & ? & I & 8 & f6 & \\
\hline MB05-136 & Sus scrofa (domestic/wild boar) & Fragment of skull & ? & 1 & 8 & f6 & \\
\hline MB05-137 & Sus scrofa (domestic/wild boar) & Fragment of skull & ? & 1 & 8 & f6 & \\
\hline MB05-145 & Sus scrofa (domestic/wild boar) & Fragment of skull & $?$ & 1 & 6 & e2 & \\
\hline MB05-146 & Sus scrofa (domestic/wild boar) & Fragment of skull & $?$ & 1 & 6 & e2 & \\
\hline MB05-160 & Sus scrofa (domestic/wild boar) & Fragment of skull & $?$ & I & 7 & b5 & \\
\hline MB05-206 & Sus scrofa (domestic/wild boar) & Fragment of skull & ? & । & 4 & $\mathrm{f} 3$ & \\
\hline MB05-207 & Sus scrofa (domestic/wild boar) & Fragment of skull & ? & । & 4 & f3 & \\
\hline MB05-208 & Sus scrofa (domestic/wild boar) & Fragment of skull & ? & । & 4 & f3 & \\
\hline MB05-218 & Sus scrofa (domestic/wild boar) & Frontal bone & $?$ & । & 6 & e1 & \\
\hline MB05-151 & Sus scrofa (domestic/wild boar) & Frontal bone & $r$ & । & 7 & c3 & \\
\hline MB07-051 & Sus scrofa (domestic/wild boar) & Incisive bone (with 12 and 13 ) & I & । & 7 & $\mathrm{f} 2$ & Teeth unerupted \\
\hline MB05-133 & Sus scrofa (domestic/wild boar) & Mandible (angle of mandible) & I & III & 18 & b1 & \\
\hline MB05-150 & Sus scrofa (domestic/wild boar) & Mandible (condylar process) & I & 1 & 5 & e6 & \\
\hline MB05-110 & Sus scrofa (domestic/wild boar) & Mandible (with dm2, dm3, and M1) & । & $\|$ & 10 & c1 & M1 erupting \\
\hline MB07-007 & Sus scrofa (domestic/wild boar) & Mandible (with dm3) & 1 & $\|$ & 9 & e3 & \\
\hline MB05-116 & Sus scrofa (domestic/wild boar) & Mandible (with I2 and C) & $r+1$ & I & 7 & c1 & Female \\
\hline MB05-011 & Sus scrofa (domestic/wild boar) & Mandible (with M2 and M3) & 1 & 1 & 6 & f1 & M3 erupting \\
\hline MB07-060 & Sus scrofa (domestic/wild boar) & Mandible (with M2 and M3) & । & । & 8 & d3 & \\
\hline MB05-118 & Sus scrofa (domestic/wild boar) & Mandible (with P2-P4) & r & I & 7 & c1 & \\
\hline MB07-001 & Sus scrofa (domestic/wild boar) & Mandible (with P3 and P4) & r & $\|$ & 12 & $\mathrm{~d} 4$ & \\
\hline MB05-038 & Sus scrofa (domestic/wild boar) & Mandible (with P4 and M1) & $r$ & I & 7 & d1 & P4 erupting \\
\hline MB05-142 & Sus scrofa (domestic/wild boar) & Maxilla (alveolar process) & ? & 1 & 6 & b6 & \\
\hline MB07-046 & Sus scrofa (domestic/wild boar) & Maxilla (alveolar process) & $r$ & $\|$ & 12 & b1 & \\
\hline MB05-002 & Sus scrofa (domestic/wild boar) & Maxilla (body of maxilla) & 1 & 1 & 5 & f5 & \\
\hline MB05-045 & Sus scrofa (domestic/wild boar) & Maxilla (body of maxilla) & $r$ & I & 7 & b5 & \\
\hline MB07-023 & Sus scrofa (domestic/wild boar) & Maxilla (body of maxilla) & $r$ & I & 6 & e3 & \\
\hline MB05-062 & Sus scrofa (domestic/wild boar) & Maxilla (with C) & I & I & 8 & f6 & Male \\
\hline MB07-008 & Sus scrofa (domestic/wild boar) & Maxilla (with C, P2, and P3) & $r$ & $\|$ & 9 & b3 & Male \\
\hline MB05-035 & Sus scrofa (domestic/wild boar) & Maxilla (with dm1) & I & I & 7 & b5 & \\
\hline MB05-067 & Sus scrofa (domestic/wild boar) & Maxilla (with dm1-dm3) & $r$ & I & 9 & a3 & \\
\hline MB05-006 & Sus scrofa (domestic/wild boar) & Maxilla (with dm1-dm3, and M1) & $r$ & I & 6 & e2 & \\
\hline MB07-056 & Sus scrofa (domestic/wild boar) & Maxilla (with dm1-dm3, and M1) & $r$ & $\|$ & 10 & d2 & \\
\hline MB05-026 & Sus scrofa (domestic/wild boar) & Maxilla (with $\mathrm{dm} 2$ and $\mathrm{dm} 3$ ) & 1 & 1 & 6 & d6 & \\
\hline MB07-057 & Sus scrofa (domestic/wild boar) & Maxilla (with dm2 and dm3) & 1 & $\|$ & 12 & b3 & \\
\hline MB05-034 & Sus scrofa (domestic/wild boar) & Maxilla (with dm3 and M1) & 1 & 1 & 7 & b5 & M1 erupting \\
\hline MB07-050 & Sus scrofa (domestic/wild boar) & Maxilla (with dm3 and M1) & $r$ & I & 7 & f2 & \\
\hline MB07-011 & Sus scrofa (domestic/wild boar) & Maxilla (with dm3, M1, and M2) & $r$ & III & 15 & c1 & \\
\hline MB05-077 & Sus scrofa (domestic/wild boar) & Maxilla (with M1 and M2) & $r$ & $\|$ & $10+11$ & a4 & M2 erupting \\
\hline MB05-114 & Sus scrofa (domestic/wild boar) & Maxilla (with M1) & I & । & 4 & e3 & \\
\hline MB05-139 & Sus scrofa (domestic/wild boar) & Maxilla (with M1) & $r$ & । & 7 & c6 & \\
\hline MB05-083 & Sus scrofa (domestic/wild boar) & Maxilla (with M2 and M3) & । & $\|$ & 10 & a5 & \\
\hline MB05-073 & Sus scrofa (domestic/wild boar) & Maxilla (with M2) & $r$ & $\|$ & 9 & a6 & M2 erupting \\
\hline MB05-108 & Sus scrofa (domestic/wild boar) & Maxilla (with M3) & $\mathrm{r}$ & $\|$ & 12 & d1 & \\
\hline MB05-003 & Sus scrofa (domestic/wild boar) & Maxilla (with P2) & 1 & I & 5 & f2 & \\
\hline MB05-102 & Sus scrofa (domestic/wild boar) & Maxilla (with P2-P4) & । & $\|$ & 13 & b1 & \\
\hline MB05-025 & Sus scrofa (domestic/wild boar) & Maxilla (with P3 and P4) & $\mathrm{r}$ & 1 & 6 & $\mathrm{f} 4$ & \\
\hline MB05-001 & Sus scrofa (domestic/wild boar) & Maxilla (with P4 and M1) & । & I & 4 & $\mathrm{f} 3$ & \\
\hline MB05-036 & Sus scrofa (domestic/wild boar) & Maxilla (with P4 and M1-M3) & I & I & 7 & b5 & M3 erupting \\
\hline
\end{tabular}


SAWADA ET AL.

Appendix 9.1 (Continued 1).

\begin{tabular}{|c|c|c|c|c|c|c|c|}
\hline Sample No. & Taxon & Skeletal part & $1 / \mathrm{r}$ & Layer & Spit $S$ & Square & Remarks \\
\hline MB05-111 & Sus scrofa (domestic/wild boar) & Maxilla (with P4 and M1-M3) & I & II & 13 & b1 & \\
\hline MB07-052 & Sus scrofa (domestic/wild boar) & Maxilla (with P4 and M1-M3) & $\mathrm{r}$ & II & 11 & $\mathrm{~d} 4$ & M3 erupting \\
\hline MB05-057 & Sus scrofa (domestic/wild boar) & Maxilla (with P4, M1, and M2) & r & I & 7 & b3 & M2 erupting \\
\hline MB05-084 & Sus scrofa (domestic/wild boar) & Maxilla (with $\mathrm{P} 4, \mathrm{M} 1$, and $\mathrm{M} 2$ ) & $\mathrm{r}$ & II & 10 & c3 & \\
\hline MB05-225 & Sus scrofa (domestic/wild boar) & Nasal bone & $?$ & 1 & 6 & a4 & \\
\hline MB05-147 & Sus scrofa (domestic/wild boar) & Nasal bone & I & I & 6 & a4 & \\
\hline MB05-148 & Sus scrofa (domestic/wild boar) & Nasal bone & $\mathrm{r}$ & 1 & 6 & b4 & \\
\hline MB05-174 & Sus scrofa (domestic/wild boar) & Temporal bone & I & 1 & $?$ & $\operatorname{cd} 7$ & \\
\hline MB05-315 & Sus scrofa (domestic/wild boar) & Temporal bone & $\mathrm{r}$ & II & 12 & $\mathrm{~d} 1$ & \\
\hline MB07-010 & Sus scrofa (domestic/wild boar) & Temporal bone & $\mathrm{r}$ & II & 11 & $a^{\prime} 3$ & \\
\hline MB05-031 & Sus scrofa (domestic/wild boar) & Tooth (fragment of incisor) & $?$ & I & 6 & c3 & \\
\hline MB05-131 & Sus scrofa (domestic/wild boar) & Tooth (fragment of LC) & $?$ & III & 18 & b1 & \\
\hline MB05-125 & Sus scrofa (domestic/wild boar) & Tooth (fragment of Ldi1 or Ldi2) & $?$ & III & 15 & a5 & \\
\hline MB05-007 & Sus scrofa (domestic/wild boar) & Tooth (fragment of molar) & $?$ & 1 & 6 & e2 & \\
\hline MB05-018 & Sus scrofa (domestic/wild boar) & Tooth (fragment of molar) & $?$ & I & 6 & b6 & \\
\hline MB05-048 & Sus scrofa (domestic/wild boar) & Tooth (fragment of molar) & $?$ & 1 & 7 & d5 & \\
\hline MB05-052 & Sus scrofa (domestic/wild boar) & Tooth (fragment of molar) & $?$ & 1 & 7 & a4 & \\
\hline MB05-059 & Sus scrofa (domestic/wild boar) & Tooth (fragment of molar) & $?$ & 1 & 8 & a3 & \\
\hline MB05-072 & Sus scrofa (domestic/wild boar) & Tooth (fragment of molar) & $?$ & II & 8 & d3 & \\
\hline MB05-082 & Sus scrofa (domestic/wild boar) & Tooth (fragment of molar) & $?$ & II & $10+11$ & a2 & \\
\hline MB05-092 & Sus scrofa (domestic/wild boar) & Tooth (fragment of molar) & $?$ & II & $10+11$ & c2 & \\
\hline MB05-096 & Sus scrofa (domestic/wild boar) & Tooth (fragment of molar) & $?$ & II & 12 & b3 & \\
\hline MB05-097 & Sus scrofa (domestic/wild boar) & Tooth (fragment of molar) & $?$ & II & 12 & b3 & \\
\hline MB05-106 & Sus scrofa (domestic/wild boar) & Tooth (fragment of molar) & $?$ & II & 14 & c1 & \\
\hline MB05-128 & Sus scrofa (domestic/wild boar) & Tooth (fragment of molar) & $?$ & III & 12 & c3 & \\
\hline MB05-130 & Sus scrofa (domestic/wild boar) & Tooth (fragment of molar) & $?$ & III & 12 & $\mathrm{~d} 2$ & \\
\hline MB05-182 & Sus scrofa (domestic/wild boar) & Tooth (fragment of molar) & $?$ & II & $10+11$ & b2 & \\
\hline MB05-251 & Sus scrofa (domestic/wild boar) & Tooth (fragment of molar) & $?$ & 1 & 7 & a4 & \\
\hline MB05-252 & Sus scrofa (domestic/wild boar) & Tooth (fragment of molar) & $?$ & 1 & 7 & a4 & \\
\hline MB05-253 & Sus scrofa (domestic/wild boar) & Tooth (fragment of molar) & $?$ & 1 & 7 & a4 & \\
\hline MB07-028 & Sus scrofa (domestic/wild boar) & Tooth (fragment of molar) & $?$ & 1 & 6 & d1 & \\
\hline MB05-126 & Sus scrofa (domestic/wild boar) & Tooth (fragment of premolar) & $?$ & III & 16 & a2 & \\
\hline MB05-132 & Sus scrofa (domestic/wild boar) & Tooth (fragment of premolar) & $?$ & III & 18 & b1 & \\
\hline MB05-064 & Sus scrofa (domestic/wild boar) & Tooth (LC) & 1 & 1 & 8 & f3 & Male \\
\hline MB05-117 & Sus scrofa (domestic/wild boar) & Tooth (LC) & I & I & 7 & $\mathrm{c} 1$ & Female \\
\hline MB05-023 & Sus scrofa (domestic/wild boar) & Tooth (Ldi2) & 1 & 1 & 6 & e4 & \\
\hline MB05-093 & Sus scrofa (domestic/wild boar) & Tooth (Ldi2) & 1 & II & 10 & f6 & \\
\hline MB05-074 & Sus scrofa (domestic/wild boar) & Tooth (Ldi2) & $\mathrm{r}$ & II & 9 & b3 & \\
\hline MB05-123 & Sus scrofa (domestic/wild boar) & Tooth (Ldi2) & $r$ & III & 15 & c3 & \\
\hline MB07-042 & Sus scrofa (domestic/wild boar) & Tooth (Ldi2) & $r$ & II & 9 & e3 & \\
\hline MB07-044 & Sus scrofa (domestic/wild boar) & Tooth (Ldi2) & $r$ & II & 13 & b3 & \\
\hline MB05-046 & Sus scrofa (domestic/wild boar) & Tooth (Ldm3) & $r$ & 1 & 7 & e6 & \\
\hline MB05-090 & Sus scrofa (domestic/wild boar) & Tooth (LI1) & I & II & $10+11$ & c1 & \\
\hline MB05-103 & Sus scrofa (domestic/wild boar) & Tooth (LI1) & 1 & II & 13 & a6 & \\
\hline MB07-015 & Sus scrofa (domestic/wild boar) & Tooth (LI1) & I & I & 8 & d1 & \\
\hline MB07-043 & Sus scrofa (domestic/wild boar) & Tooth (LI1) & 1 & II & 9 & b3 & \\
\hline MB05-076 & Sus scrofa (domestic/wild boar) & Tooth (LI1) & r & ॥ & 9 & f6 & \\
\hline MB05-015 & Sus scrofa (domestic/wild boar) & Tooth (LI2) & I & 1 & 6 & b4 & \\
\hline MB05-075 & Sus scrofa (domestic/wild boar) & Tooth (LI2) & I & II & 9 & d3 & \\
\hline MB05-065 & Sus scrofa (domestic/wild boar) & Tooth (LI2) & $r$ & I & 8 & b5 & \\
\hline MB05-124 & Sus scrofa (domestic/wild boar) & Tooth (LI2) & $r$ & III & 15 & a5 & \\
\hline MB05-030 & Sus scrofa (domestic/wild boar) & Tooth (LI3) & $r$ & 1 & 6 & c3 & \\
\hline MB05-129 & Sus scrofa (domestic/wild boar) & Tooth (LM1) & I & III & 12 & a5 & \\
\hline MB05-070 & Sus scrofa (domestic/wild boar) & Tooth (LM1) & $r$ & 1 & 9 & a2 & Unerupted \\
\hline MB05-091 & Sus scrofa (domestic/wild boar) & Tooth (LM1) & $r$ & ॥ & $10+11$ & $\mathrm{c} 2$ & \\
\hline MB07-048 & Sus scrofa (domestic/wild boar) & Tooth (LM2) & 1 & 1 & 10 & d4 & \\
\hline MB07-058 & Sus scrofa (domestic/wild boar) & Tooth (LM2) & 1 & III & 14 & $a^{\prime} 3$ & \\
\hline MB05-010 & Sus scrofa (domestic/wild boar) & Tooth (LM2) & $r$ & 1 & 6 & f3 & \\
\hline MB07-049 & Sus scrofa (domestic/wild boar) & Tooth (LM3) & I & 1 & 10 & $\mathrm{~d} 4$ & \\
\hline MB07-059 & Sus scrofa (domestic/wild boar) & Tooth (LM3) & 1 & III & 14 & $a^{\prime} 3$ & \\
\hline MB05-080 & Sus scrofa (domestic/wild boar) & Tooth (LM3) & r & ॥ & $10+11$ & a2 & \\
\hline MB05-021 & Sus scrofa (domestic/wild boar) & Tooth (LP2) & $r$ & 1 & 6 & b6 & \\
\hline MB05-058 & Sus scrofa (domestic/wild boar) & Tooth (M3 fr) & $?$ & 1 & 7 & b3 & \\
\hline MB05-040 & Sus scrofa (domestic/wild boar) & Tooth (UC) & I & 1 & 7 & e1 & Female \\
\hline MB07-004 & Sus scrofa (domestic/wild boar) & Tooth (UC) & $\mathrm{r}$ & I & 7 & $\mathrm{c} 1$ & Male \\
\hline MB07-025 & Sus scrofa (domestic/wild boar) & Tooth (Udi1) & 1 & II & 13 & f4 & \\
\hline MB05-019 & Sus scrofa (domestic/wild boar) & Tooth (Udm2) & I & 1 & 6 & b6 & \\
\hline MB05-004 & Sus scrofa (domestic/wild boar) & Tooth (Udm3) & I & I & 5 & e6 & \\
\hline
\end{tabular}




\section{FAUNAL REMAINS}

\begin{tabular}{|c|c|c|c|c|c|c|c|}
\hline \multicolumn{8}{|c|}{ Appendix 9.1 (Continued 2). } \\
\hline Sample No. & Taxon & Skeletal part & $1 / r$ & Layer & Spit $S$ & Square & Remarks \\
\hline MB05-033 & Sus scrofa (domestic/wild boar) & Tooth (Udm3) & $r$ & I & 7 & b5 & \\
\hline MB05-014 & Sus scrofa (domestic/wild boar) & Tooth (UI1) & I & । & 6 & b4 & \\
\hline MB05-050 & Sus scrofa (domestic/wild boar) & Tooth (Ul1) & I & I & 7 & a3 & \\
\hline MB07-039 & Sus scrofa (domestic/wild boar) & Tooth (Ul1) & I & I & 7 & c3 & \\
\hline MB05-022 & Sus scrofa (domestic/wild boar) & Tooth (UI2) & $\mathrm{r}$ & I & 6 & e1 & \\
\hline MB05-008 & Sus scrofa (domestic/wild boar) & Tooth (UI3) & I & I & 6 & e2 & \\
\hline MB05-155 & Sus scrofa (domestic/wild boar) & Tooth (UI3) & $\mathrm{r}$ & I & 6 & a3 & \\
\hline MB05-017 & Sus scrofa (domestic/wild boar) & Tooth (UM1) & I & 1 & 6 & b6 & Unerupted \\
\hline MB05-032 & Sus scrofa (domestic/wild boar) & Tooth (UM1) & I & 1 & 7 & b5 & \\
\hline MB05-066 & Sus scrofa (domestic/wild boar) & Tooth (UM1) & I & I & 8 & f2 & Unerupted \\
\hline MB05-028 & Sus scrofa (domestic/wild boar) & Tooth (UM2) & I & 1 & 6 & c2 & \\
\hline MB05-060 & Sus scrofa (domestic/wild boar) & Tooth (UM2) & । & 1 & 8 & a3 & \\
\hline MB05-127 & Sus scrofa (domestic/wild boar) & Tooth (UM2) & I & III & 17 & $\mathrm{c} 2$ & \\
\hline MB07-053 & Sus scrofa (domestic/wild boar) & Tooth (UM2) & I & $\|$ & 7 & $a^{\prime} 6$ & \\
\hline MB07-054 & Sus scrofa (domestic/wild boar) & Tooth (UM2) & I & ॥ & 11 & a1 & \\
\hline MB05-051 & Sus scrofa (domestic/wild boar) & Tooth (UM2) & $\mathrm{r}$ & 1 & 7 & a4 & Unerupted \\
\hline MB05-107 & Sus scrofa (domestic/wild boar) & Tooth (UM3) & । & ॥ & 14 & a1 & \\
\hline MB05-122 & Sus scrofa (domestic/wild boar) & Tooth (UM3) & I & III & $14+15$ & $\mathrm{a} 2 \mathrm{~b} 2$ & \\
\hline MB05-054 & Sus scrofa (domestic/wild boar) & Tooth (UM3) & $\mathrm{r}$ & I & 7 & a3 & Unerupted \\
\hline MB05-061 & Sus scrofa (domestic/wild boar) & Tooth (UP1) & $\mathrm{r}$ & I & 8 & a3 & \\
\hline MB05-020 & Sus scrofa (domestic/wild boar) & Tooth (UP2) & I & I & 6 & b6 & \\
\hline MB05-013 & Sus scrofa (domestic/wild boar) & Tooth (UP2) & $\mathrm{r}$ & 1 & 6 & b4 & Unerupted \\
\hline MB05-079 & Sus scrofa (domestic/wild boar) & Tooth (UP2) & $\mathrm{r}$ & ॥ & $10+11$ & a4 & \\
\hline MB05-078 & Sus scrofa (domestic/wild boar) & Tooth (UP3) & $\mathrm{r}$ & ॥ & $10+11$ & a4 & \\
\hline MB05-068 & Sus scrofa (domestic/wild boar) & Tooth (UP4) & I & I & 9 & d1 & \\
\hline MB05-105 & Sus scrofa (domestic/wild boar) & Tooth (UP4) & I & ॥ & 14 & b1 & \\
\hline MB05-081 & Sus scrofa (domestic/wild boar) & Tooth (UP4) & $\mathrm{r}$ & ॥ & $10+11$ & a2 & \\
\hline MB05-109 & Muntiacus muntjak (barking deer) & Antler & $?$ & II & 11 & a1 & \\
\hline MB05-112 & Muntiacus muntjak (barking deer) & Frontal bone and antler & I & 1 & 5 & d5 & \\
\hline MB05-172 & Cervus sp. (deer) & Antler & $?$ & I & 7 & d5 & \\
\hline MB05-087 & Cervus sp. (deer) & Mandible (with dm3) & $\mathrm{r}$ & ॥ & $10+11$ & b1 & \\
\hline MB05-156 & Cervus sp. (deer) & Occipital bone & $\mathrm{m}$ & I & 7 & b5 & \\
\hline MB05-043 & Cervus sp. (deer) & Tooth (fragment of premolar) & $?$ & 1 & 7 & $\mathrm{f} 4$ & \\
\hline MB05-044 & Cervus sp. (deer) & Tooth (fragment of premolar) & $?$ & 1 & 7 & $\mathrm{f} 4$ & \\
\hline MB05-101 & Cervus sp. (deer) & Tooth (LM3) & $\mathrm{r}$ & II & 13 & b2 & \\
\hline MB05-094 & Cervus sp. (deer) & Tooth (UM1) & $\mathrm{r}$ & ॥ & 11 & e3 & \\
\hline MB05-009 & Cervus sp. (deer) & Tooth (UM2) & I & 1 & 6 & e2 & Unerupted \\
\hline MB05-095 & Cervus sp. (deer) & Tooth (UM2) & $\mathrm{r}$ & ॥ & 11 & e3 & \\
\hline MB05-089 & Cervus sp. (deer) & Tooth (UM3) & $\mathrm{r}$ & II & 10 & $\mathrm{f} 4$ & \\
\hline MB05-056 & Cervus sp. (deer) & Tooth (UP2) & I & 1 & 7 & b3 & \\
\hline MB05-086 & Cervus sp. (deer) & Tooth (UP2) & $r$ & ॥ & $10+11$ & a1 & \\
\hline MB07-005 & Bos sp. (bos) and/or Bubalus sp. (water buffalo) & Tooth (fragment of molar) & I & ॥ & 11 & $\mathrm{~d} 2$ & \\
\hline MB05-055 & Bos sp. (bos) and/or Bubalus sp. (water buffalo) & Tooth (LP3) & I & 1 & 7 & b3 & \\
\hline MB05-027 & Medium-size Ruminantia (family indeterminate) & Tooth (fragment of molar) & $?$ & 1 & 6 & c2 & \\
\hline MB05-330 & Cetacea (whale/dolphin) & Limb bone (shaft) & $?$ & III & 15 & a1 & \\
\hline MB05-171 & Cetacea (whale/dolphin) & Vertebra & $\mathrm{m}$ & $\|$ & 12 & a6 & \\
\hline
\end{tabular}




\section{SAWADA ET AL.}

Appendix 9.2 Raw data measurements of the Man Bac mammal remains ( $\mathrm{mm}$ ).

\begin{tabular}{|c|c|c|c|c|c|c|c|c|c|}
\hline \multicolumn{10}{|c|}{ Sus scrofa (domestic/wild boar) } \\
\hline Sample No. & Skeletal part & $1 / r$ & $\begin{array}{c}\text { LP2-LP4 } \\
\text { length }\end{array}$ & $\begin{array}{c}\text { UM1 } \\
\text { length }\end{array}$ & $\begin{array}{c}\text { UM2 } \\
\text { length }\end{array}$ & $\begin{array}{c}\text { UM3 } \\
\text { length }\end{array}$ & $\begin{array}{l}\text { LM1 } \\
\text { length }\end{array}$ & $\begin{array}{c}\text { LM2 } \\
\text { length }\end{array}$ & $\begin{array}{c}\text { LM3 } \\
\text { length }\end{array}$ \\
\hline MB05-006 & Maxilla (with dm1-dm3, and M1) & $r$ & & 19.70 & & & & & \\
\hline MB05-010 & Tooth (LM2) & $\mathrm{r}$ & & & & & & 23.84 & \\
\hline MB05-011 & Mandible (with M2 and M3) & 1 & & & & & & 22.54 & 45.00 \\
\hline MB05-017 & Tooth (UM1) & 1 & & 19.33 & & & & & \\
\hline MB05-028 & Tooth (UM2) & 1 & & & 20.26 & & & & \\
\hline MB05-032 & Tooth (UM1) & 1 & & 17.69 & & & & & \\
\hline MB05-036 & Maxilla (with P4 and M1-M3) & 1 & & & 26.34 & & & & \\
\hline MB05-038 & Mandible (with P4 and M1) & r & & & & & 18.93 & & \\
\hline MB05-051 & Tooth (UM2) & r & & & 23.39 & & & & \\
\hline MB05-054 & Tooth (UM3) & r & & & & 33.89 & & & \\
\hline MB05-057 & Maxilla (with $\mathrm{P} 4, \mathrm{M} 1$, and $\mathrm{M} 2$ ) & $\mathrm{r}$ & & 15.35 & & & & & \\
\hline MB05-060 & Tooth (UM2) & 1 & & & 23.26 & & & & \\
\hline MB05-066 & Tooth (UM1) & 1 & & 17.19 & & & & & \\
\hline MB05-070 & Tooth (LM1) & $\mathrm{r}$ & & & & & 18.97 & & \\
\hline MB05-077 & Maxilla (with M1 and M2) & r & & 17.50 & 21.11 & & & & \\
\hline MB05-080 & Tooth (LM3) & $\mathrm{r}$ & & & & & & & 43.90 \\
\hline MB05-083 & Maxilla (with M2 and M3) & 1 & & & & 33.47 & & & \\
\hline MB05-107 & Tooth (UM3) & I & & & & 34.10 & & & \\
\hline MB05-110 & Mandible (with dm2, dm3, and M1) & 1 & & & & & 18.28 & & \\
\hline MB05-111 & Maxilla (with P4 and M1-M3) & 1 & & 16.75 & 23.27 & 37.10 & & & \\
\hline MB05-118 & Mandible (with P2-P4) & $r$ & 39.73 & & & & & & \\
\hline MB05-122 & Tooth (UM3) & 1 & & & & 38.72 & & & \\
\hline MB05-127 & Tooth (UM2) & I & & & 22.36 & & & & \\
\hline MB05-129 & Tooth (LM1) & 1 & & & & & 18.88 & & \\
\hline MB07-011 & Maxilla (with dm3, M1, and M2) & $\mathrm{r}$ & & 18.49 & 22.95 & & & & \\
\hline MB07-048 & Tooth (LM2) & I & & & & & & 22.90 & \\
\hline MB07-049 & Tooth (LM3) & 1 & & & & & & & 43.84 \\
\hline MB07-050 & Maxilla (with dm3 and M1) & $\mathrm{r}$ & & 18.18 & & & & & \\
\hline MB07-052 & Maxilla (with P4 and M1-M3) & r & & 17.66 & 22.98 & & & & \\
\hline MB07-053 & Tooth (UM2) & 1 & & & 22.85 & & & & \\
\hline MB07-054 & Tooth (UM2) & 1 & & & 21.58 & & & & \\
\hline MB07-060 & Mandible (with M2 and M3) & 1 & & & & & & & 38.97 \\
\hline Mean & & & - & 17.78 & 22.76 & 35.46 & 18.77 & 23.09 & 42.93 \\
\hline SD & & & - & 1.25 & 1.56 & 2.32 & 0.33 & 0.67 & 2.69 \\
\hline \multicolumn{10}{|c|}{ Cervus sp. (deer) } \\
\hline Sample No. & Skeletal part & $1 / \mathrm{r}$ & $\begin{array}{c}\text { UM1 } \\
\text { length }\end{array}$ & $\begin{array}{c}\text { UM2 } \\
\text { length }\end{array}$ & $\begin{array}{c}\text { LM3 } \\
\text { length }\end{array}$ & & & & \\
\hline MB05-094 & Tooth (UM1) & $r$ & 22.32 & & & & & & \\
\hline MB05-095 & Tooth (UM2) & $r$ & & 27.16 & & & & & \\
\hline MB05-101 & Tooth (LM3) & $r$ & & & 31.79 & & & & \\
\hline
\end{tabular}

